Ann. Biol. anim. Bioch. Biophys., 1977, 17 (4), 633-636.

\title{
Influence de l'axénie sur la composition en acides aminés des fèces chez le rat et l'agneau
}

\author{
par Etiennette COMBE, R. PION
}

avec la collaboration technique d'Elisabeth DEBRAS, Annick JAFFEUX et Marie-Claude VALLUY ainsi que A. SELLE et M. SALLAS ;

Laboratoire d'Ełude du Métabolisme Azoté, I.N.R.A., Theix, Saint Genès Champanelle 63110 Beaumont.

Summary. Fecal amino acid composition in germfree and conventional rats and lambs.

Apparent dry matter, nitrogen and aminoacid (AA) digestibilities were higher in germfree ( $g f)$ and conventional (cv) lambs than in $g f$ and $c v$ rats. Faecal dry matter, nitrogen and AA excretions were lower in gf than in $\mathrm{cv}$ environment for lambs fed UHTsterilized milk. On the other hand, faecal excretions were higher in gf environment for rats fed an autoclaved casein diet.

In percentage of total nitrogen, non-aminoacid nitrogen was higher in feces from gf animals than in those from cr animals. The differences between the AA composition of lamb faeces, food and microbial or endogenous proteins suggest that most of the faecal AA come from endogenous secretions.

Some bacterial products might contribute to faecal AA of cr lambs, as suggested by the low value of the average relative difference (ARD) between AA excretion in $g f$ and $c r$ lambs and the amino acid composition of the intestinal bacteria. On the other hand, nitrogen fecal excretion from rats fed a poorly digestible casein diet seemed to be increased by non-digested material of dietary origin in gf rats; the microflora might contribute to digestion of dietary protein, thus resulting in an increase of the apparent nitrogen and aminoacid digestibilities.

La microflore hébergée dans le tube digestif, et en particulier dans le caecum des animaux, contribue à l'utilisation digestive des matières azotées d'origine alimentaire et d'origine endogène. Nous avons essayé de faire le bilan de son action en comparant les excrétions fécales des animaux axéniques et holoxéniques. Nous avons utilisé des animaux d'espèces et d'état physiologique différents : agneaux âgés de 15 jours nourris de lait de vache stérilisé par Ultra Haute Température et des rats âgés de deux mois ayant reçu un régime autoclavé, à base de caséine. Les conditions expérimentales précises ont été reportées par ailleurs (Combe, 1973 ; Combe 1976).

Quel que soit l'environnement microbien les coefficients d'utilisation digestive apparente sont beaucoup plus élevés chez les agneaux que chez les rats. Ils atteignent respectivement 97,78 et 95,74 pour la matière sèche $(M S)$ et la matière azotée (MA) 
du lait ingéré par les agneaux axéniques et sont significativement plus élevés que chez les holoxéniques utilisés comme témoins (tabl. 1). Les agneaux hébergeant une microflore excrètent donc davantage que les agneaux axéniques pour une même quantité ingérée. Par contre les coefficients d'utilisation digestive obtenus antérieurement (Combe, 1973) chez les rats n'atteignent que 88,7 p. 100 pour la MS ef 85,1 p. 100 pour la MA chez les holoxéniques, et sont nettement plus faibles chez les rats axéniques. Cependant compte tenu des quantités d'azote excrétées par l'urine (240 et $292 \mathrm{mg} / \mathrm{j} /$ rat axénique et holoxénique), les excrétions totales de composés azotés sont voisines chez les rats axéniques et chez les rats holoxéniques ( 360 et $380 \mathrm{mg} \mathrm{N} / \mathrm{j}$ ). Afin d'élucider les raisons de ces résultats à priori contradictoires nous avons comparé l'influence de la microflore sur la composition en acides aminés des fèces des agneaux ef des rats en relation avec la nature et la qualité de leur alimentation.

TABLEAU 1

Coefficient d'utilisation digesfive chez les agneaux ef les rats hébergeant ou non une microflore

\begin{tabular}{|c|c|c|c|c|}
\hline \multirow{2}{*}{$\begin{array}{l}\text { CUD apparent : } \\
\frac{\text { I-E }}{\text { I p. } 100}\end{array}$} & \multicolumn{2}{|c|}{ Agneaux } & \multicolumn{2}{|c|}{ Rats } \\
\hline & Holoxéniques & Axéniques & Holoxéniques & Axéniques \\
\hline $\begin{array}{l}\text { MS } \\
\text { MA }\end{array}$ & $\begin{array}{l}96,1 \pm 0,64 * * \\
93,3 \pm 1,20 *\end{array}$ & $\begin{array}{l}97,8 \pm 1,28 \\
95,7 \pm 2,30\end{array}$ & $\begin{array}{l}88,7 \\
85,1\end{array}$ & $\begin{array}{l}83,6 \\
80,5\end{array}$ \\
\hline
\end{tabular}

Différence significative au seuil : **0,05; ${ }^{*} 0,1$.

Le tableau 2 montre que dans le cas de jeunes agneaux, les fèces des axéniques sont plus paurres en azote ( $p .100$ MS) que celles des holoxéniques, alors que dans le cas des rats, les fèces des axéniques sont plus riches en azote que celles des holoxéniques. La proportion d'azote provenant des acides aminés par rapport à l'azote total trouvé dans les fèces est de 72 et 64 p. 100 chez les animaux holoxéniques alors qu'elle est toujours plus faible chez les axéniques, la plus grande différence apparaissant chez les rats.

La composition en acides aminés des fèces des agneaux est très différente de: celle des fèces des rats. L'écart moyen relatif (emr) entre les compositions centésimales: des acides aminés des fèces des agneaux et des rats calculé comme le proposent Patureau-Mirand ef al. (1977) atteint 30 p. 100. Les teneurs en thréonine, sérine et proline: des fèces des agneaux axéniques sont nettement plus élevées que celles des fèces des: agneaux holoxéniques ; au contraire les teneurs en lysine, phénylalanine et méthionine sont plus faibles chez les axéniques. Les faibles proportions de phénylalanine, tyrosine, leucine, méthionine et acide glutamique des fèces holoxéniques sont compensées par des proportions élevées d'acide aspartique, thréonine, sérine, glycine et: alanine. Chez les axéniques, ces différences sont amplifiées pour la thréonine et la: sérine ; alors que les proportions de lysine sont voisines dans le lait et les fèces. Le 
régime utilisé par les agneaux éłait constitué de lait de vache (36 p. $100 \mathrm{MA} / \mathrm{MS})$ stérilisé par Ultra Haute Température. Ce procédé ne modifie guère la digestibilité du mélange protéines-lactose ef les éléments du régime sont bien absorbés. La composition en acides aminés des fèces est très différente de celle du laił : l'écart moyen relatif atteint 35 p. 100 dans le cas des agneaux holoxéniques et 46 p. 100 dans le cas des axéniques. Dans ce dernier cas les matières azotées fécales doivent être en majorité d'origine endogène ; elles sont accompagnées d'un supplément vraisemblablement constitué de corps bactériens et de produits de leur métabolisme dans le cas des holoxéniques.

TABLEAU 2

Composition en acides aminés* des fèces et de l'aliment des agneaux et des rats holoxéniques et axéniques

\begin{tabular}{|c|c|c|c|c|c|c|}
\hline & \multicolumn{3}{|c|}{ Agneaux } & \multicolumn{3}{|c|}{ Rats } \\
\hline & \multicolumn{2}{|c|}{ Fèces } & \multirow{2}{*}{ Lait } & \multicolumn{2}{|c|}{ Fèces } & \multirow{2}{*}{ Aliment } \\
\hline & Holo. & Ax. & & Holo. & Ax. & \\
\hline 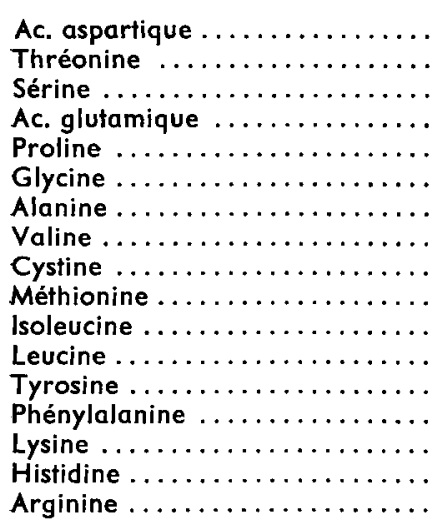 & $\begin{array}{r}12,59 \\
6,54 \\
5,23 \\
15,54 \\
6,33 \\
4,45 \\
6,28 \\
5,73 \\
2,90 \\
1,99 \\
3,74 \\
6,41 \\
2,80 \\
3,82 \\
8,77 \\
2,09 \\
4,78\end{array}$ & $\begin{array}{r}10,30 \\
14,39 \\
7,62 \\
14,34 \\
8,28 \\
4,26 \\
5,13 \\
5,55 \\
3,08 \\
1,50 \\
3,27 \\
5,51 \\
2,68 \\
2,79 \\
5,02 \\
2,20 \\
4,07\end{array}$ & $\begin{array}{r}7,33 \\
3,82 \\
4,89 \\
22,85 \\
9,73 \\
1,63 \\
3,24 \\
5,62 \\
0,93 \\
2,68 \\
4,57 \\
8,67 \\
4,78 \\
5,12 \\
8,60 \\
2,43 \\
3,12\end{array}$ & $\begin{array}{r}8,90 \\
4,45 \\
8,04 \\
20,09 \\
4,57 \\
4,33 \\
4,76 \\
6,24 \\
2,78 \\
3,46 \\
6,30 \\
6,92 \\
4,51 \\
3,15 \\
5,19 \\
1,79 \\
3,77\end{array}$ & $\begin{array}{r}10,6 \\
5,31 \\
8,90 \\
20,65 \\
5,61 \\
4,71 \\
3,66 \\
5,24 \\
2,84 \\
2,54 \\
5,01 \\
5,31 \\
6,36 \\
2,32 \\
5,01 \\
1,94 \\
3,3\end{array}$ & $\begin{array}{r}7,16 \\
3,70 \\
5,03 \\
20,19 \\
8,86 \\
2,71 \\
3,63 \\
6,78 \\
0,73 \\
3,24 \\
5,08 \\
8,91 \\
4,94 \\
5,28 \\
6,68 \\
2,71 \\
4,36\end{array}$ \\
\hline N AA p. $100 \mathrm{~N}$ total ........... & 71,71 & 60,00 & & 64,4 & 52,7 & \\
\hline$N$ total $\times 6,25$ p. 100 MS $\ldots \ldots \ldots$ & 42,19 & 34,16 & & 28,79 & 35,24 & \\
\hline
\end{tabular}

* La teneur de chaque acide aminé est exprimée en p. 100 de la somme des acides aminés dosés.

Dans les fèces des rats les différences de composition en acides aminés liées à la présence de bactéries sont plus faibles. La valeur de l'écart relatif moyen entre les acides aminés provenant des fèces des rats axéniques et des fèces des rats holoxéniques n'atteint que 18 p. 100. Les fèces des rats axéniques sont cependant nettement plus riches en certains acides aminés dont la tyrosine, la proline, la thréonine et plus pauvres en méthionine, phénylalanine ef leucine que les fèces des rats holoxéniques. L'écart moyen relatif entre les compositions en acides aminés des fèces et celle de 
l'aliment est plus faible dans le cas des rats que dans celui des agneaux. Il n'atteint que 26 p. 100 pour les rats holoxéniques et 33 p. 100 pour les axéniques. Les teneurs en sérine, glycine, alanine, isoleucine, acide aspartique et thréonine des fèces des rats holoxéniques sont plus élevées que dans l'aliment, alors que les teneurs en proline, phénylalanine et histidine sont plus faibles dans les fèces que dans l'aliment. La composition en acides aminés des fèces des rats holoxéniques est très voisine (emr $=20 p .100)$ de celle trouvée par Mendes-Pereira ef al. (1975) dans les fèces de rats ayant ingéré un aliment renfermant de la caséine chauffée en présence de glucose. La faible digestibilité observée dans les deux cas liée au traitement thermique doit aboutir à la présence dans les fèces d'une quantité notable de matières azotées d'origine alimentaire. Celles-ci seraient partiellement digérées par la microflore dans le cas des holoxéniques. L'absence de microflore conduirait à une augmentation de l'excrétion d'azote d'origine alimentaire, qui ne serait compensée que pour une faible proportion par l'absence de corps bactériens dans les fèces. Ceci est en accord avec la présence dans les contenus de caecum de rats axéniques de quantités importantes non seulement d'acides aminés libres, de peptides à poids moléculaire élevé mais aussi de protéines solubles (Pion, Valenza et Combe, 1971).

L'effet de la microflore est très différent selon la digestibilité des matières azotées alimentaires. Dans le cas d'un régime très digestible la présence de corps microbiens dans les fèces entraîne une augmentation de l'excrétion azotée chez les animaux holoxéniques, alors que l'action de la microflore sur les composés non digérés provenant des protéines de lait chauffées consommées par les rats entraînerait une diminution des quantités d'azote alimentaire excrétées très supérieures à la quantité excrétée sous forme de corps microbiens.

Commission CNERNA Digestion-Absorption, Tours, 13 novembre 1976.

Remerciements. - Nous remercions le Laboratoire de Microbiologie qui nous a préparé les agneaux axéniques en isolateurs, la Station de Recherches sur l'Elevage des ruminants qui nous a permis d'utiliser les agneaux holoxéniques, ainsi que J. Prugnaud pour la réalisation du dosage des acides aminés.

\section{Références}

COMBE E., 1973. Nitrogen metabolism in germfree rats. In HENEGAN J. B., Germfree research 305-308. Acad. Press, New York.

COMBE E., 1976. Influence de la microflore intestinale sur la composition en acides aminés des fèces des agneaux. C. R. Soc. Biol., 170, 59-65.

MENDES-PEREIRA E., KUNACHOWICZ H., PION R., PRUGNAUD J., 1975. Effet du chauffage en présence ou en absence de glucose sur l'utilisation digestive ef métabolique des acides aminés de la caséine. C. R. Soc. Biol., 169, 1511-1517.

PATUREAU-MIRAND P., TOULLEC R., GUILLOTEAU P., PION R., 1977. Influence de la nature des protéines alimentaires sur la composition en acides aminés des fèces du veau préruminant. Ann. Biol. anim. Bioch. Biophys., 17, 71-83.

PION R., VALENZA C., COMBE E., 1971. Matières azotées des contenus de cæcum de rat: méthodes d'études ef résultats obtenus; influence de l'état axénique. Ann. Biol. anim. Bioch. Biophys., 11, 337-338. 